\title{
Adrenal tumours: 10-year experience of a tertiary cancer centre
}

\author{
Subbiah Shanmugam*, Sujay Susikar, Gerald Anand Raja, Kishore Kumar Reddy
}

Department of Surgical Oncology, Kilpauk Medical College, Chennai, Tamil Nadu, India

Received: 30 May 2021

Revised: 06 July 2021

Accepted: 07 July 2021

\author{
*Correspondence: \\ Dr. Subbiah Shanmugam, \\ E-mail: subbiahshanmugam67@gmail.com
}

Copyright: ( ) the author(s), publisher and licensee Medip Academy. This is an open-access article distributed under the terms of the Creative Commons Attribution Non-Commercial License, which permits unrestricted non-commercial use, distribution, and reproduction in any medium, provided the original work is properly cited.

\begin{abstract}
Adrenal tumours are rare neoplasm. The prevalence of adrenal tumours is estimated to be $3 \%$ in those older than 50 years and 6\% in those older than 60 years. Diagnostic work-up should assess autonomous hormone production and differentiate between benign and malignant lesions. In 19 patients presenting with adrenal tumours from 2010-2020, 9 $(47.4 \%)$ were male patients and $10(52.6 \%)$ female patients with a mean age of 44.6 years. Presenting complaints include headache and hypertension in $8(42.1 \%)$ patients, pain abdomen in $4(21.1 \%)$ patients, incidentally diagnosed in $5(26.3 \%)$ patients and $2(10.5 \%)$ patients presented with mass per abdomen. Pheochromocytoma was seen in 10 $(52.6 \%)$ patients, adrenocortical carcinoma was seen in $5(26.3 \%)$ patients, adenoma was seen in $3(15.8 \%)$ patients each and angiomyolipoma was seen in $1(5.3 \%)$ patient. Open adrenalectomy was done in $13(68.4 \%)$ patients and laparoscopic adrenalectomy was done in $5(26.3 \%)$ patients. One patient presented with multiple metastases and was inoperable. Adrenal tumours are rare neoplasms often presenting with nonspecific symptoms. The majority are nonfunctioning tumours with an incidence in the $5^{\text {th }}$ or $6^{\text {th }}$ decade. In our study pheochromocytoma is most common followed by adrenocortical carcinoma. Laparoscopic adrenalectomy is now the gold standard for small and mediumsized tumours.
\end{abstract}

Keywords: Adrenal adenoma, Pheochromocytoma, Incidentaloma

\section{INTRODUCTION}

Adrenal tumours are rare neoplasm. The prevalence of adrenal tumours is estimated to be $3 \%$ in those older than 50 years and $6 \%$ in those older than 60 years. ${ }^{1}$

Early diagnosis and management of adrenal tumours have undergone a significant change with the advances in biochemical evaluation, diagnostic imaging techniques, and progress in the field of minimally invasive surgery. Appropriate assessment of an adrenal mass is an essential prerequisite before its definitive treatment. $^{2}$

Diagnostic work-up should assess autonomous hormone production and differentiate between benign and malignant lesions. Evaluation of cortisol and (nor) metanephrine secretion should be performed in all patients presenting with an adrenal mass. ${ }^{3-6}$ The possibility of adrenal insufficiency in case of bilateral lesions should be kept in mind. Screening for primary hyperaldosteronism by measuring plasma aldosterone concentration and plasma renin activity should be performed if hypertension and/or hypokalaemia are present. $^{4,5}$ Functional cortical neoplasms commonly present with hypercortisolism (Cushing syndrome), followed by virilization, hyperaldosteronism, and rarely feminization. ${ }^{7}$ It is difficult to differentiate adrenocortical adenoma (ACA) from adrenocortical carcinoma (ACC) by hormonal evaluation, but certain endocrine manifestations should increase clinical suspicion for ACC. In particular, patients with virilisation or feminization, especially in the presence of hypercortisolism (mixed syndromes), have an increased likelihood of an underlying adrenocortical malignancy. ${ }^{8}$ 
Attenuation on unenhanced CT is the most accurate predictor to differentiate between benign and malignant masses. If the lesion's attenuation value is $\leq 10$ Hounsfield units (HU), malignancy is extremely unlikely. ${ }^{9}$ If $\mathrm{HU}>10$, a contrast wash-out sequence should be performed. A washout $>50 \%$ after 15 minutes is indicative of adrenal adenoma. The combined use of attenuation measurement and washout values can be used to discriminate adenomas from other adrenal masses with $98 \%$ sensitivity and $92 \%$ specificity. ${ }^{10}$

The percutaneous adrenal biopsy is rarely done. It has high false-negative rates and risk of complications. Only role of percutaneous biopsy in the evaluation of an adrenal mass is confirming metastatic disease in patients with known extra-adrenal malignancy and confirming the diagnosis of adrenocortical carcinoma when radical resection is deemed not possible..$^{3,5}$

In our study, the demographic characteristics of adrenal tumours presenting in our centre for oncology over 10year period were analysed.

\section{CASE SERIES}

There were 19 patients presenting with adrenal tumours from 2010-2020. Out of which $9(47.4 \%)$ were male patients and $10(52.6 \%)$ female patients. The age of the patients was in the range of 9-61 years, with a mean of 44.6 years. Presenting complaints include headache and hypertension in $8(42.1 \%)$ patients, pain abdomen in 4 $(21.1 \%)$ patients, incidentally diagnosed in $5(26.3 \%)$ patients and $2(10.5 \%)$ patients presented with mass per abdomen.

Table 1: Patient characteristics.

\begin{tabular}{|ll|}
\hline Variables & $\mathbf{N}(\%)$ \\
\hline No. of patients & 19 \\
\hline Age (years) & \\
\hline Range & $9-61$ \\
\hline Mean & 44.6 \\
\hline Sex & $9(47.4)$ \\
\hline Male & $10(52.6)$ \\
\hline Female & \\
\hline Presenting complaints & $8(42.1)$ \\
\hline Headache, hypertension & $4(21.1)$ \\
\hline Pain abdomen & $5(26.3)$ \\
\hline Incidental & $2(10.5)$ \\
\hline Mass per abdomen & \\
\hline Diagnosis & $10(52.6)$ \\
\hline Pheochromocytoma & $5(26.3)$ \\
\hline Adrenocortical carcinoma & $3(15.8)$ \\
\hline Adrenocortical adenoma & $1(5.3)$ \\
\hline Angiomyolipoma & \\
\hline Surgery & $13(68.4)$ \\
\hline Open adrenalectomy & $5(26.3)$ \\
\hline Laparoscopic adrenalectomy & $1(5.3)$ \\
\hline Inoperable & \\
\hline & \\
\hline
\end{tabular}

Among the 19 patients, pheochromocytoma was seen in $10(52.6 \%)$ patients, adrenocortical carcinoma was seen in $5(26.3 \%)$ patients, adenoma was seen in $3(15.8 \%)$ patients each, and angiomyolipoma was seen in $1(5.3 \%)$ patient. Open adrenalectomy was done in $13(68.4 \%)$ patients and laparoscopic adrenalectomy was done in 5 $(26.3 \%)$ patients. One patient presented with multiple metastases and was inoperable.

\section{DISCUSSION}

Differential diagnosis of an adrenal mass is extensive, with the majority being non-secreting cortical adenomas (41\%), others include metastases (19\%), adrenocortical carcinoma (10\%), myelolipoma (9\%), pheochromocytoma $(8 \%)$, benign lesions like adrenal cysts forming the remainder. ${ }^{11}$ In our study pheochromocytoma was most common followed by adrenocortical carcinoma which could be due to our institute being a tertiary cancer centre where complicated cases are referred.

Adrenocortical carcinoma (ACC) is a rare malignancy with a poor prognosis. The reported incidence is $0.5-2$ cases per million populations per year. ${ }^{12,13}$ It is more common in females and can occur at any age with a peak in the fifth and sixth decades of life, the mean age of presentation being 51 years. ${ }^{13}$ In our study, it was seen in 5 out of 19 patients (26.3\%), 3 female patients and 2 male patients. All patients were $>50$ years old.

Pheochromocytoma is a rare tumour arising from the adrenal medulla which is more common between 40-59 years with no sex preponderance. Its prevalence is 2.13 per 100000 populations. ${ }^{14}$ They are commonly functional and $5-7 \%$ of incidentalomas are diagnosed as pheochromocytoma. ${ }^{15,16}$ In study pheochromocytoma was seen in 10 patients $(52.6 \%)$ of which 4 were male patients and 6 female patients.

Adrenal adenomas are benign neoplasms of the adrenal cortex. Based on CT scan findings, the reports of the prevalence of adrenal incidentalomas have been $0.35 \%$ to $1.9 \% .{ }^{17}$ However, an autopsy series reported a prevalence of $2.3 \% .^{18}$ Approximately $54 \%$ of adrenal incidentalomas are adrenal adenomas. Adrenal adenomas are more commonly seen in women (55\%) compared to men $(45 \%)$. The mean age for diagnosis is 57 years (range 16 to 83 years). ${ }^{19}$ In our study $3(15.8 \%)$ patients 2 male and one female had adrenal adenomas.

Adrenal angiomyolipomas are extremely rare with only five cases reported. ${ }^{20-24}$ They are classified in the family of perivascular epithelioid tumours (so-called PEComas). It may be difficult to differentiate this tumour from adrenal carcinomas on imaging studies and even upon histological examination. The presence of both adipose tissue and cells positively staining for muscle and melanoma markers like HMB45, MART1/MelanA and smooth muscle actin are required for definitive 
diagnosis. ${ }^{25}$ In our study angiomyolipoma was seen in 1 $(7.2 \%)$ patient.

Since Gagner et al described the first laparoscopic adrenalectomy (LA), minimally invasive surgical approach replaced open procedure in the management of small and medium-sized adrenal lesions. ${ }^{26}$ Contraindications include tumours larger than $12 \mathrm{~cm}$ likely containing malignancy and local tumour invasion into adjacent structures. In our study 13 (68.4\%) patients underwent open adrenalectomy, 5 (26.3\%) patients underwent laparoscopic adrenalectomy and one patient was inoperable.

\section{CONCLUSION}

Adrenal tumours are rare neoplasms often presenting with nonspecific symptoms. The majority are nonfunctioning tumours, with an incidence in the $5^{\text {th }}$ or $6^{\text {th }}$ decade. In our study pheochromocytoma is most common followed by adrenocortical carcinoma. Laparoscopic adrenalectomy is now the gold standard for small and medium-sized tumours.

Funding: No funding sources

Conflict of interest: None declared

Ethical approval: Not required

\section{REFERENCES}

1. Else T, Kim AC, Sabolch A, Raymond VM, Kandathil A, Caoili EM et al. Adrenocortical carcinoma. Endocrine reviews. 2014;35(2):282-326.

2. Khanna S, Priya R, Bhartiya SK, Basu S, Shukla VK. Adrenal tumors: An experience of 10 years in a single surgical unit. Indian j cancer. 2015;52(3):475.

3. Daneshmand S, Quek ML. Adrenal myelolipoma: diagnosis and management. J Urol. 2006;3:71-4.

4. Grumbach MM, Biller BM, Braunstein GD, Campbell KK, Carney JA, Godley PA et al. Management of the clinically inapparent adrenal mass (incidentaloma). Ann internal med. 2003;138(5):424-9.

5. Terzolo M, Stigliano A, Chiodini I, Loli P, Furlani L, Arnaldi $\mathrm{G}$ et al. AME position statement on adrenal incidentaloma. Eur J endocrinol. 2011;164(6):851-70.

6. Bittner JG, Brunt LM. Evaluation and management of adrenal incidentaloma. J Surgical Oncol. 2012;106(5):557-64.

7. Fassnacht M, Libé R, Kroiss M, Allolio B. Adrenocortical carcinoma: a clinician's update. Nature Reviews Endocrinol. 2011;7(6):323-35.

8. Cordera F, Grant C, Van Heerden J, Thompson G, Young W. Androgen-secreting adrenal tumors. Surgery. 2003;134(6):874-80.

9. Nieman LK. Approach to the patient with an adrenal incidentaloma. J Clin Endocrinol Metabolism. 2010;95(9):4106-13.
10. Hamrahian AH, Ioachimescu AG, Remer EM, Motta-Ramirez G, Bogabathina H, Levin HS et al. Clinical utility of noncontrast computed tomography attenuation value (Hounsfield units) to differentiate adrenal adenomas/hyperplasia from non-adenomas: Cleveland Clinic experience. J Clin Endocrinol Metabolism. 2005;90(2):871-7.

11. Aron DC. The adrenal incidentaloma: Disease of modern technology and public health problem. Rev Endocr Metab Disord. 2001;2:335-42.

12. Wooten MD, King DK. Adrenal cortical carcinoma. Epidemiology and treatment with mitotane and a review of the literature. Cancer. 1993;72(11):3145-55.

13. Kebebew E, Reiff E, Duh QY, Clark OH, McMillan A. Extent of disease at presentation and outcome for adrenocortical carcinoma: have we made progress? World J Surg. 2006;30(5):872-78.

14. Kim JH, Moon H, Noh J, Lee J, Kim SG. Epidemiology and prognosis of pheochromocytoma/paraganglioma in Korea: a nationwide study based on the National Health Insurance Service. Endocrinol Metabolism. 2020;35(1):157.

15. Hong AR, Kim JH, Park KS, Kim KY, Lee JH, Kong $\mathrm{SH}$ et al. Optimal follow-up strategies for adrenal incidentalomas: reappraisal of the 2016 ESE-ENSAT guidelines in real clinical practice. Eur $\mathbf{J}$ Endocrinol. 2017;177:475-83.

16. Mantero F, Terzolo M, Arnaldi G, Osella G, Masini AM, Ali A, et al. A survey on adrenal incidentaloma in Italy. Study Group on Adrenal Tumors of the Italian Society of Endocrinology. J Clin Endocrinol Metab. 2000;85:637-44.

17. Mahmood E, Anastasopoulou C. Adrenal Adenoma. In: StatPearls [Internet]. Treasure Island (FL): StatPearls Publishing. 2020.

18. Barzon L, Sonino N, Fallo F, Palu G, Boscaro M. Prevalence and natural history of adrenal incidentalomas. Eur

Endocrinol. 2003;149(4):273-85.

19. Mantero F, Terzolo M, Arnaldi G, Osella G, Masini AM, Alì A et al. A survey on adrenal incidentaloma in Italy. Study Group on Adrenal Tumors of the Italian Society of Endocrinology. J Clin Endocrinol Metab. 2000;85(2):637-44.

20. D’Antonio A, Caleo A, Caleo O, De Dominicis G, Boscaino A. Monotypic epithelioid angiomyolipoma of the adrenal gland: an unusual site for a rare extrarenal tumor. Ann Diagnostic Pathol. 2009;13(5):347-50.

21. Godara R, Vashist MG, Singla SL, Garg P, Sen J, Mathur SK et al. Adrenal angiomyolipoma: a rare entity. Indian j urol. 2007;23(3):319.

22. Hu H, Xi X. Giant adrenal angiomyolipoma. J Clin Endocrinol Metabolism. 2012;97(11):3835-6.

23. Sutter R, Boehler A, Willmann JK. Adrenal angiomyolipoma in lymphangioleiomyomatosis. Eur Radiol. 2007;17(2):565-6. 
24. Yener O, Ozcelik A. Angiomyolipoma of the right adrenal gland. Surgery. 2011;102743:2.

25. Kerkhofs TM, Roumen RM, Demeyere TB, Van der Linden AN, Haak HR. Adrenal tumors with unexpected outcome: a review of the literature. Int $\mathrm{j}$ endocrinol. 2015;2015.
26. Gagner M, Lacroix A, Bolte E. Laparoscopic adrenalectomy in Cushing's syndrome and pheochromocytoma. N Engl J Med. 1992;327:1033.

Cite this article as: Shanmugam S, Susikar S, Raja GA, Reddy KK. Adrenal tumours: 10-year experience of a tertiary cancer centre. Int Surg J 2021;8:2420-3. 